\title{
Chemical compositions and anti-inflammatory activities of essential oils from Aster spathulifolius and Vitex rotundifolia maxim
}

\author{
Chunsuk Kim, Hee Jung Bu, Sun Joo Lee, Chang-Gu Hyun and Nam Ho Lee* \\ Department of Chemistry and Cosmetics, Jeju National University, Jeju, South Korea.
}

\begin{tabular}{l} 
ARTICLE INFO \\
\hline Article history: \\
Received on: $04 / 08 / 2014$ \\
Revised on: $15 / 08 / 2014$ \\
Accepted on: $22 / 09 / 2014$ \\
Available online: $30 / 10 / 2014$ \\
\hline Key words: \\
Eessential oils, chemical \\
composition, Aster \\
spathulifolius, Vitex \\
rotundifolia, anti- \\
inflammation.
\end{tabular}

\begin{abstract}
The essential oils were prepared from Aster spathulifolius (ASE) and Vitex rotundifolia (VRE) by hydrodistillation and their chemical compositions were investigated by GC-MS. Analysis of ASE provided 15 components and eight of which were identified sesquiterpene compounds. The major components in ASE included germacrene D (35.1\%), trans-caryophyllene (15.9\%) and trans-phytol (14.9\%). On the other hand, VRE provided manoyl oxide (14.3\%), $\alpha$-terpineol (13.1\%) and $\alpha$-pinene (10.0\%) as major ingredients. To assess the anti-inflammatory effects of the essential oils, the production of nitric oxide (NO) and tumor necrosis factor (TNF)- $\alpha$ were monitored using lipopolysaccharide (LPS)-activated RAW 264.7 macrophages. In this test, ASE and VRE were appeared to suppress both NO and TNF- $\alpha$ synthesis in dose-dependent manner. The results indicate that VRE and ASE could be useful in cosmetic applications as natural products possessing antiinflammatory efficacy.
\end{abstract}

\section{INTRODUCTION}

The essential oils are mixture of volatile compounds possessing aromatic odours derived from mainly plant flowers or leaves. Terpenoids, isoprene-based natural compounds, are in most cases the major chemical components in the essential oils. Identification of the individual chemical constituents in the oils could be accomplished by the use of gas chromatography-mass spectrometry (GC-MS), where the relative retention times/indices and fragmentation patterns were comparatively analyzed for the specific GC peaks (Zellner et al., 2010). Essential oils have been commonly applied in aromatherapy where the aromatic compounds are expected to have some curative effects. In order to identify new biological benefits in human healthcare, essential oils have been investigated in broad range of applications (Buchbauer 2010). We are continuously conducting research projects on essential oils prepared from plants in Jeju, an island of biodiversity located at the southernmost part of Korea (Kim et al., 2013; Kim et al., 2011). In this study, essential oils from Aster spathulifolius (ASE) and Vitex rotundifolia (VRE) by hydrodistillation were investigated for their chemical compositions along with their anti-inflammatory activities.

* Corresponding Author

Email:namho@jejunu.ac.kr
A. spathulifolius Maxim. (Asteraceae) is a herb distributed in southern part of Japan and Korea. $V$. rotundifolia belonging to Lamiaceae is a woody shrub native to seashore throughout the Pacific. Both perennial plants commonly occur in the coastal area of Jeju Island (Lee et al., 2001). Antiviral efficacies have been studied on the extract from A. spathulifolius against the influenza infection (Won et al., 2013). Diterpenes with cytotoxic properties have been isolated from the aerial part of $A$. spathulifolius (Lee et al., 2005). Inhibition effects of the extract of $V$. rotundifolia on inflammatory gene expression in human epithelial cells have been reported (Sohn et al., 2009).

While chemical composition of essential oil from $V$. rotundifolia by distillation in the co-presence of water and petroleum ether has been analyzed (Jang et al., 2000), antiinflammatory effects of VRE have not been explored yet.

\section{MATERIALS AND METHODS}

\section{Plant material}

The plants A. spathulifolius (sample no. 323) and $V$. rotundifolia (sample no. 324) were collected at the coastal area of Jeju Island during November and December in 2012. Voucher specimens have been deposited at the Natural Product Chemistry Laboratory, Jeju National University. The specimens were identified by Dr. H. C. Kim (plant taxonomist). 


\section{Extraction of essential oils}

The leaves of A. spathulifolius and the stems of $V$. rotundifolia were used as the materials for thisexperiments. Both samples were freeze-dried, and were subjected to water distillation for $6 \mathrm{~h}$ using a Clevenger-type apparatus. The obtained essential oils were dried over anhydrous sodium sulphate, and were stored in a sealed vial at $4{ }^{\circ} \mathrm{C}$ during the experiment. The obtained oil yields were about $0.12 \%$ and $0.05 \%(\mathrm{w} / \mathrm{w})$ for $A$. spathulifolius and $V$. rotundifolia respectively.

\section{Gas chromatography-mass spectrometry analysis}

Gas chromatographic analyses were performed on a Shimatzu GC-MS ultra 2010 gas chromatograph equipped with an non-polar Rtx-5MS column $(30 \mathrm{~m} \times 0.25 \mathrm{~mm}$ $0.25 \mu \mathrm{m})$ and a split-splitless injection port (split mode). The temperature was set at $40{ }^{\circ} \mathrm{C}$ for $5 \mathrm{~min}$, ramped to $100{ }^{\circ} \mathrm{C}$ at $10{ }^{\circ} \mathrm{C} / \mathrm{min}$ and further to $300{ }^{\circ} \mathrm{C}$ at $2{ }^{\circ} \mathrm{C} / \mathrm{min}$, and maintained at $300{ }^{\circ} \mathrm{C}$ for $20 \mathrm{~min}$. Compounds were identified by their retention indices on the column and by GC-MS library. Results of the analysis for ASE and VRE were given in Tables 1 and 2.

\section{Cell culture and viability}

Murine RAW 264.7 macrophages were cultured in Dulbecco's modified Eagle's medium (DMEM) supplemented with fetal bovine serum (10\%), penicillin (100 U/mL), and streptomycin $(100 \mu \mathrm{g} / \mathrm{mL})$ in an incubator at $37{ }^{\circ} \mathrm{C}$ in a humidified atmosphere of $95 \%$ air and $5 \% \mathrm{CO}_{2}$. Cell viability was determined by the 3-(4,5-dimethylthiazol-2-yl)-2,5-diphenyltetrazolium bromide (MTT) assay.

RAW 264.7 cells were cultured in 96-well plates for $18 \mathrm{~h}$, followed by treatment with various concentrations of the ASE and VRE. After $24 \mathrm{~h}$ incubation, MTT was added to the medium for $4 \mathrm{~h}$. After removing the supernatant, formazan crystals were dissolved in DMSO and absorbance was measured at $540 \mathrm{~nm}$. The percentage of cells showing cytotoxicity was determined relative to the control group.

\section{Determination of nitric oxide (NO) products}

After pre-incubation of RAW 264.7 cells $\left(2.0 \times 10^{5}\right.$ cells $/ \mathrm{mL})$ with LPS $(1 \mu \mathrm{g} / \mathrm{mL})$ for 24 hours, the quantity of nitrite in the culture medium was measured as an indicator of NO production. Briefly, $100 \mu \mathrm{L}$ of cell culture medium was mixed with $100 \mu \mathrm{L}$ of Griess reagent (1\% sulfanilamide and $0.1 \%$ naphthylethylenediamine dihydrochloride in $2.5 \%$ phosphoric acid), the mixture with different concentration $(3.13,6.25,12.5$ and $25.0 \mu \mathrm{g} / \mathrm{mL})$ of oils was incubated at room temperature for $10 \mathrm{~min}$, and the absorbance at $540 \mathrm{~nm}$ was measured in a microplate reader. Fresh culture medium was used as a blank in every experiment. The quantity of nitrite was determined from a sodium nitrite standard curve.

\section{Measurement of Pro-inflammatory Cytokine (TNF- $\alpha$ ) Production}

The inhibitory effects of ASE and VRE on proinflammatory cytokine (TNF- $\alpha$ ) production in LPS-treated RAW 264.7 cells were determined by ELISA as described in the manufacturer's instructions (R \& D Systems, Minneapolis, MN).

\section{RESULTS AND DISCUSSION}

Water-distilled essential oils from the leaves of $A$. spathulifolius (ASE) and the stems of $V$. rotundifolia (VRE) were analyzed by GC and GC-MS. The identified compounds with their percentage were summarized in Tables 1 and 2. The GC/MS retention indices were calculated using a homologous series of $\mathrm{C}_{5^{-}}$ $\mathrm{C}_{26}$ normal-alkanes. Analysis of ASE afforded fifteen components representing $100 \%$ of the total oil (Table 1). A cyclic sesquiterpene, germacrene D (35.1\%), was identified as the major component. The other important ingredients include transcaryophyllene (15.9\%), trans-phytol (14.9\%), (-)-caryophyllene oxide (6.0\%) and 6,10,14-trimethyl-2-pentadecanone (5.6\%). ASE is characterized by high contents of sesquiterpene and diterpene compounds.

Table 1: Composition of essential oil from A. spathulifolius (ASE).

\begin{tabular}{cclc}
\hline RT & RI & \multicolumn{1}{c}{ Name } & $\%$ \\
\hline 32.9 & 1418 & trans-Caryophyllene & 15.9 \\
34.5 & 1459 & (Z)- $\beta$-farnesene & 1.2 \\
35.4 & 1483 & Germacrene D & 35.1 \\
35.9 & 1495 & bicyclogermacrene & 4.1 \\
36.7 & 1529 & Methyl (Z)-dec-2-en-4,6-diyonate & 2.0 \\
36.8 & 1537 & -Cadinene & 2.2 \\
38.5 & 1641 & Spathulenol & 1.1 \\
38.6 & 1655 & (-)-Caryophyllene oxide & 6.0 \\
40.6 & 1831 & $\alpha$-Cadinol & 1.2 \\
41.9 & 1920 & Stearaldehyde & 1.4 \\
43.1 & 1923 & 2-(1-E-propenyl)-4-methoxyphenyl & 2-methyl \\
& & butanoate & 4.3 \\
44.7 & 1948 & Neophytadiene & 1.4 \\
44.9 & 1951 & 6,10,14-Trimethyl-2-pentadecanone & 5.6 \\
49.0 & 2096 & $\alpha$-Podocarpene & 3.5 \\
50.2 & 2263 & trans-phytol & 14.9 \\
\hline Total & & & 100 \\
\hline
\end{tabular}

In the oil of $V$. rotundifolia (VRE), twelve components were verified through a typical library search selecting only components with matches exceeding $80 \%$, which represented about $70.7 \%$ of total oil (Table 2). The major components detected in VRE were manoyl oxide (14.3\%), $\alpha$-terpineol (13.1\%), $\alpha$-pinene $(10.0 \%)$, dehydroabietane $(5.9 \%)$ and sabinene $(5.1 \%)$. As seen in Table 2, VRE consisted mainly of mono- and diterpenes. Previous report on the composition of oil of $V$. rotundifolia has indicated its major components as $\alpha$-pinene (13.2\%), $\alpha$-terpineol (10.6\%), 1,8-cineole $(4.4 \%)$ and manoyl oxide $(4.0 \%)$. Comparing our results to the literature though the compositions for both oils are almost identical but the percentage of each component showed so report (Jang et al., 2000), even me discrepancies. This could be attributed to the difference of the distillation method between this study and the literature one. 
Table 2: Composition of essential oil from $V$. rotundifolia (VRE).

\begin{tabular}{|c|c|c|c|}
\hline RT & RI & Name & $\%$ \\
\hline 10.4 & 932 & $\alpha$-Pinene & 10.0 \\
\hline 11.9 & 973 & Sabinene & 5.1 \\
\hline 11.9 & 974 & 2 - $\beta$-Pinene & 3.1 \\
\hline 13.9 & 1029 & 1,8-Cineole & 4.9 \\
\hline 19.5 & 1188 & 1-Methyl-4-(2-propanol-2-yl)-cyclohexene & 1.9 \\
\hline 29.6 & 1357 & $\alpha$-Terpineol & 13.1 \\
\hline 47.2 & 1987 & $\beta$-iso-Methyl ionone & 2.2 \\
\hline 47.3 & 1988 & Biformene & 4.3 \\
\hline 47.5 & 1992 & Manoyl oxide & 14.3 \\
\hline 49.3 & 2128 & Dehydroabietane & 5.9 \\
\hline 50.2 & 2256 & trans-Phytol & 3.6 \\
\hline 50.4 & 2309 & Thunbergol & 2.3 \\
\hline Total & & & 70.7 \\
\hline
\end{tabular}
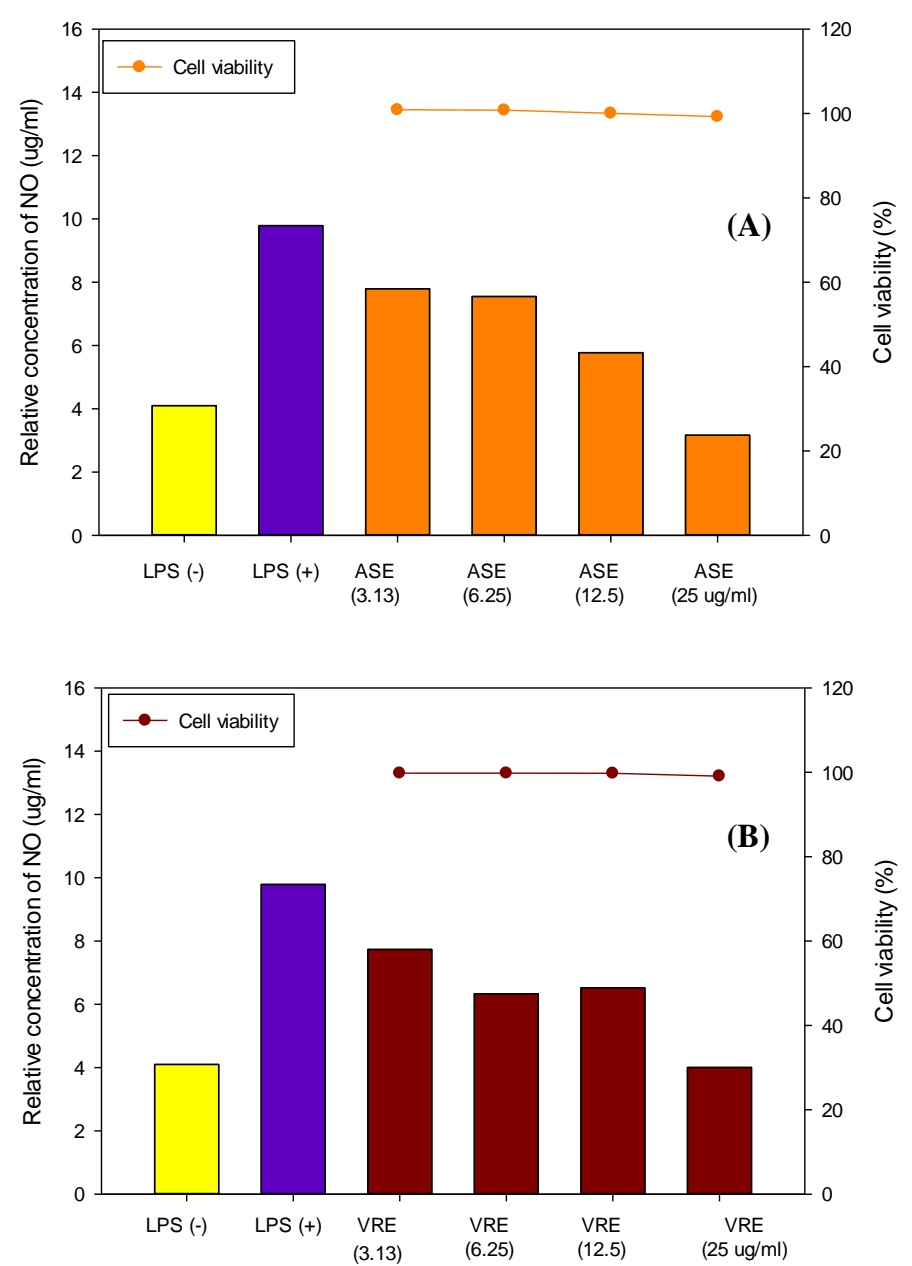

Fig 1. Nitric oxide (NO) production and cell viability for ASE (A) and VRE (B) in RAW 264.7 cells. RAW 264.7 cells $\left(2.0 \times 10^{4} \mu \mathrm{g} / \mathrm{mL}\right)$ were preincubated with LPS for $24 \mathrm{~h}$, and nitrite was assayed after treatment of different concentration $(3.13,6.25,12.5$ and $25.0 \mu \mathrm{g} / \mathrm{mL})$ of oils. The absorbance was measured at $540 \mathrm{~nm}$ with a spectrophotometer (Power Wave; Bio-tek, Winooski, VT).

In order to validate the use of oils as an antiinflammatory agent, their effects on the production of nitric oxide (NO) was investigated (Yoon et al., 2010). Nitric oxide is an endogenous free radical species synthesised from L-arginine by nitric oxide synthase (NOS) in various animal cells and tissues. After exposure to triggers including lipopolysaccharide (LPS),
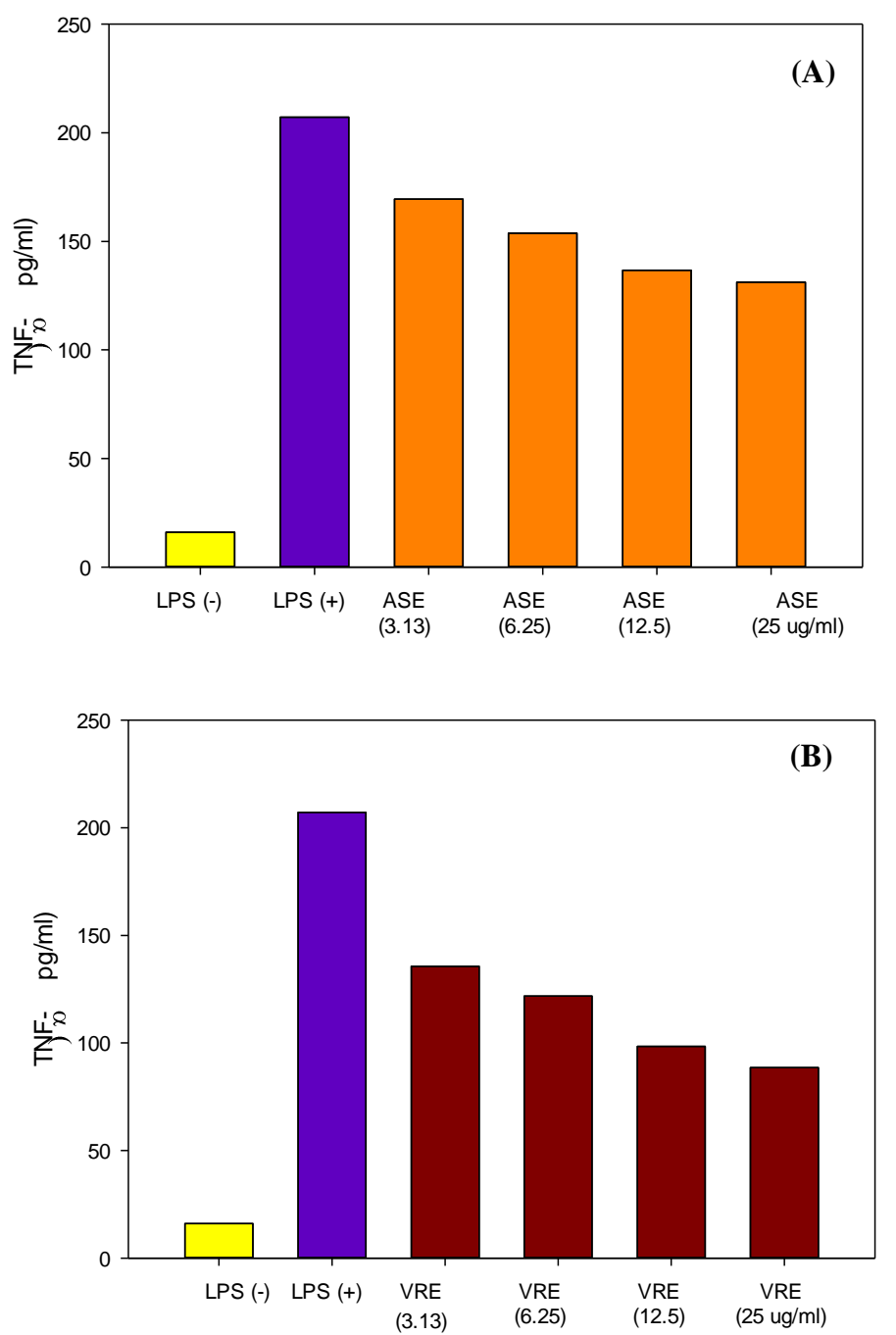

Fig 2. Effects of ASE (A) and VRE (B) on TNF- $\alpha$ production in LPSstimulated RAW 264.7 cells. TNF- $\alpha$ production in LPS-treated RAW 264.7 cells were determined by ELISA after treatment of different concentration $(3.13,6.25,12.5$ and $25.0 \mu \mathrm{g} / \mathrm{mL})$ of oils as described in the manufacturer's instructions (R \& D Systems, Minneapolis, MN).

inducible NOS (iNOS) can be generated in inflammation-related cells such as macrophages (Murakami 2009).

Thus, measuring NO production may be a useful method for assessing the anti-inflammatory effects of essential oils. In this experiment, the nitrite concentration was determined in the supernatant after treatment with LPS $(1 \mu \mathrm{g} / \mathrm{mL})$ alone or co-treated with ASE and VRE (3.13 to $25 \mu \mathrm{g} / \mathrm{mL}$ ) for $24 \mathrm{~h}$ using Griess reagent. As shown in Fig. 1, ASE and VRE suppressed LPSinduced NO formation significantly in dose-dependent fashion. ASE and VRE exhibited similar potencies in this assay providing about $60 \%$ decrease of NO production at $25.0 \mu \mathrm{g} / \mathrm{mL}$ concentration.

In order to inspect the oils' cytotoxicity, cell viability was assessed using an MTT assay. As shown in the same figure, the numbers of viable macrophage cells were rarely decreased by the ASE and VRE indicating their non-toxic properties. This indicated that the inhibitory effects by the oils were not due to 
cytotoxicity or cell death, but were derived by other antiinflammatory mechanisms. TNF- $\alpha$ is a cytokine primarily produced by monocytes and macrophages eliciting septic shock and inflammation. The inhibition of TNF- $\alpha$ production or function is a key mechanism in the control of inflammation (Feldmann 2008). Levels of TNF- $\alpha$ in the culture supernatants were measured using ELISA kits. LPS ( $1 \mu \mathrm{g} / \mathrm{mL})$ stimulation for $24 \mathrm{~h}$ led to marked increases of TNF- $\alpha$ levels in the cell supernatants. However, treatment ASE and VRE for $24 \mathrm{~h}$ exhibited a concentration-dependent inhibition of TNF- $\alpha$ production in RAW 264.7 cells (Fig. 2).

In this test, VRE exhibited relatively potent activities compared to ASE. In summary, essential oils ASE and VRE were chemically analyzed by GC-MS and their major components were identified terpenoids including germacrene D and manoyl oxide respectively. The anti-inflammatory effects were monitored by the production of nitric oxide (NO) and TNF- $\alpha$ using RAW 264.7 macrophages. In this test, ASE and VRE were appeared to suppress both NO and TNF- $\alpha$ synthesis in dose-dependent manner. The results indicate that VRE and ASE could be useful in cosmetic applications such as aromatherapy as natural products possessing anti-inflammatory efficacy.

\section{ACKNOWLEDGMENTS}

This research was financially supported by the Ministry of Trade, Industry and Energy (MOTIE) and Korea Institute for Advancement of Technology (KIAT) through the Research and Development for Regional Industry.

\section{REFERENCES}

Buchbauer G. Biological activities of essential oils. In Handbook of Essential Oils. Science, Technology, and Applications. Ed. Baser KHC, Bachbauer G. 2010; CRC Press, New York: p 235-280.

Feldmann M. Many cytokines are very useful therapeutic targets in disease. J Clin Invest 2008; 118: 3533-3536.

Jang SJ, Kim YH, Kim MK, Kim KW, Yun SE. Essential oil composition from leaves, flowers, stems, and fruits of Vitex totundifolia L. fil. J. Korean Soc Agric Chem Biotechnol 2000; 45: 101-107.
Kim SS, Kim JE, Hyun CG, Lee NH. Neolitsea aciculate essential oil inhibits drug-resistant skin pathogen growth and Propionibacterium acnes-induced inflammatory effects of human monocyte leukemia. Nat Prod Commun 2011; 6: 1193-1198.

Kim CS, Lee SJ, Hyun CG, Lee NH. Chemical constituents of supercritical extracts from Prunus chinensis, Zanthoxylum pipertium and their anti-inflammatory activities. Int J Pharmacol 2013; 9: 258-264.

Lee SO, Choi SZ, Choi SU, Lee KC. Labdane diterpenes from Aster spathulifolius and their cytotoxic effects on human cancer cell lines. J Nat Prod 2005; 68: 1471-1474.

Lee YN, Lee KS, Shim YM. Wild plants od Jeju Island. 2001; Yeomiji Botanical Garden, Jejudo, Korea: p 414, 481.

Murakami A. Chemoprevention with phtochemicals targeting inducible nitric oxide synthase. Forum Nutr 2009; 61: 193-203.

Sohn SH, Ko E, Oh BG, Kim SH, Kim Y. Inhibition effects of Vitex rotundifolia on inflammatory gene expression in A549 human epithelial cells. Ann Allergy Asthma Immunol 2009; 103: 152-159.

Won JN, Lee SY, Song DS, Poo HR. Antiviral activity of the plant extracts from Thuja orientalis, Aster spathulifolius, and Pinus thunbergii against influenza virus A/PR/8/34. J Microbiol Biotechnol 2013; 23: 125-130.

Yoon WJ, Lee NH, Hyun CG. Limonene suppresses lipopolysaccharide-induced protection of nitric oxide, prostaglandin $\mathrm{E}_{2}$, and pro-inflammatory cytokines in RAW 264.7 macrophages. J Oleo Sci 2010; 59: 415-421.

Zellenr BA, Dugo P, Dugo G, Mondello L. Analysis of essential oils. In Handbook of Essential Oils. Science, Technology, and Applications. Ed. Baser KHC, Bachbauer G. 2010; CRC Press, New York: p 151-184.

\section{How to cite this article:}

Chunsuk Kim, Hee Jung Bu, Sun Joo Lee, Chang-Gu Hyun and Nam Ho Lee. Chemical Compositions and Anti-inflammatory Activities of Essential Oils from Aster spathulifolius and Vitex rotundifolia Maxim. J App Pharm Sci, 2014; 4 (10): 012-015. 